\title{
The Effect of "SELF-HELP Packages" on Post Stroke Depression among Ischemic Stroke Survivors
}

\author{
Fitria Handayani ${ }^{1}$, Setyowati Setyowati ${ }^{2}$, Dwi Pudjonarko ${ }^{3,4}$, Dian Ratna Sawitri ${ }^{5}$ \\ ${ }^{1}$ Department of Nursing, Faculty of Medicine, Universitas Diponegoro, Semarang, Indonesia \\ ${ }^{2}$ Department of Maternity and Women's Health, Faculty of Nursing, University of Indonesia, Indonesia \\ ${ }^{3}$ Departement of Neurology, Faculty of Medicine, Universitas Diponegoro, Semarang, Indonesia \\ ${ }^{4}$ Kariadi General Hospital, Semarang, Indonesia \\ ${ }^{5}$ Faculty of Psychology, Universitas Diponegoro, Semarang, Indonesia \\ Corresponding Author: Fitria Handayani (fitria.handayani@fk.undip.ac.id)
}

Received: 19 June 2020

Revised: 16 December 2020

Accepted: 26 December 2020

\begin{abstract}
Background: There are several factors that contribute to Post Stroke Depression (PSD). Since a single intervention is proven ineffective to deal with PSD, an intervention which includes biological, psychological, social, and spiritual aspects ("SELF-HELP Packages"), therefore, needs to be established.

Purpose: The purpose of the study was to investigate the effect of "SELF HELP Packages" intervention on PSD among ischemic stroke survivors after three months from onset and its effect after confounding variables were controlled.

Methods: This study was a pre and post quasi-experiment with a control group, involving 34 ischemic stroke survivors each group. The inclusion criteria were survivors after three months from ischemic stroke, no aphasia, having a good hearing, and having Mini Mental Status Examination (MMSE) score of $\geq 22$. GRID-HAMD 17, Multidimensional Scale of Perceived Social Support (MSPSS), and Barthel-Index were used to measure PSD, social support, and functional status respectively. "SELF-HELP Packages" intervention was delivered in three sessions, namely information delivery, discussion and activity. Statistical analyses were conducted using McNemar test, chisquare and logistic regression.

Results: The result showed that "SELF-HELP Packages" considerably decreased PSD in the intervention group $(p=0.004)$. There were also significant differences on PSD after the intervention between two groups $(p=0.008)$. Logistic regression showed that 'SELF-HELP Package" had no effect on PSD when other confounding variables were controlled $(p=0.075, \mathrm{OR}=0.288,95 \%$ CI $0.073-1.135)$.

Conclusion: SELF-HELP Packages" should be applied in providing the nursing intervention among stroke ischemic survivors in clinical setting. A longer period of time for the intervention is recommended for the next study to obtain a more robust result.
\end{abstract}

Keywords: Ischemic stroke; post stroke depression; "SELF-HELP Packages" intervention

How to Cite: Handayani, F., Setyowati, S., Pudjonarko, D., \& Sawitri, D. R. (2020). The effect of "SELF-HELP packages" on post stroke depression among ischemic stroke survivors. Nurse Media Journal of Nursing, 10(3), 361-375. doi:10.14710/nmjn.v10i3.31014

Permalink/DOI: https://doi.org/10.14710/nmjn.v10i3.31014 
Nurse Media Journal of Nursing, 10(3), 2020, 362

\section{BACKGROUND}

World Health Organization (WHO) stated that stroke is the fifth rank cause of mortality and contributes to different health status between males and females (World Health Organization, 2019). The prevalence of stroke in Central Java is 11 per miles in 2018 (Ministry of Health of the Republic of Indonesia, 2018), while the number in Semarang City is also high, reaching for 8,808 cases (Health Office of Semarang City, 2020). This high prevalence of stroke should become more concern for management.

Stroke will impact many conditions, such as handicap, family and economic burden and Post Stroke Depression (PSD) (Donkor, 2018). The pattern of PSD is unique in which the incident increases at fourth week after onset and peaks at 14th week (three months) after onset (Gbiri, Akinpelu, \& Odole, 2010). Furthermore, PSD possibly continues up to six months, or more than one year after stroke onset (Chau et al., 2010; De Wit et al., 2008). Specific pattern of PSD is explained as a high prevalence of PSD after three month from onset, which ranges from 17.7 to $47.7 \%$ (Handayani \& Pudjonarko 2015).

Post Stroke Depression after three months from onset will impact on functional status and handicap, continuous depression, suicidal thought, and fatigue (Bartoli, Di Brita, Crocamo, Clerici, \& Carràl, 2018; Kang et al., 2018; Lincoln et al., 2013). PSD leads to fatigue 1.5 year after stroke (Lerdal et al., 2011), and low quality of life 5 years after stroke (Kielbergerova et al., 2015). PSD also contributes to mortality rate (Bartoli et al., 2018; Hackett, Köhler, O'Brien, \& Mead, 2014). Some medicines are prescribed to reduce PSD, namely deanxit, fluoxetine, setraline, paroxetine, and citalopram, and their effects will continue to six-eight weeks after treatment (Loubinoux et al., 2012). Although the patients consume medicines, PSD will re-occur in three months to two years after stroke (Guiraud et al., 2016; Kang et al., 2018; Yuan et al., 2012).

Two studies reported that some interventions could not significantly decrease PSD. A study which delivered high intensity of exercise among ischemic stroke patients had no impact on PSD (Holmgren, Lindström, Gosman-Hedström, Nyberg, \& Wester, 2010). Another intervention was cognitive rehabilitation among stroke patients in long term health care facilities which was reported to be significant to reduce Geriatric Depression Scale (GDS). Nevertheless, the minimum number of participants in this study (Sakamoto et al., 2018) causing the generalization of the result could not be concluded. These studies revealed that single interventions were not effective to reduce PSD.

Other studies using complex interventions, including aspects of biology, psychology, social, and spirituality show good outcomes. Zimmermann et al., (2016) point out that a complex intervention which consists of biological, psychological, and social aspects, increases perceived self-efficacy and better clinical outcome of anxiety, depression or somatization symptoms. Byrne et al. (2020) claim that Ready to Reduce Risk (3R) complex intervention improves clinical lifestyles of the patients with cardiovascular diseases. The result of these studies supports the claim that complex interventions including biological, psychological, social and spiritual aspects have an opportunity to accomplish the modified behaviour and clinical improvements (Medical Research Council, 2014). 
Apart from the interventions to decrease PSD, several factors are reported to affect PSD, of which, in this study, are considered as the confounding factors. A review concludes that a factor related to PSD after three months from stroke onset is social support (Handayani, Setyowati, Pudjonarko, \& Sawitri, 2019). A study from Shi et al. (2015) also shows that the predictors of PSD are cognitive aspects and stroke recurrent. Furthermore, functional status is independently associated with PSD after three months from stroke onset (Ojagbemi \& Owolabi, 2013). Another relating factor with PSD is Brain Derived Neurotropic Factor (BDNF). Research showed that BDNF has an important role in maintaining neural function, plasticity and neurogenesis regulation (Silakarma \& Sudewi, 2019). Specifically, BDNF is related with PSD among ischemic stroke survivor after three months from onset (Li et al., 2014).

Previous studies involving single interventions showed insignificant effect to decrease PSD. On the other hand, complex interventions were reported to yield good outcomes in patients with psychological problems and cardiovascular diseases. In addition, there are several factors contribute to PSD such as social or family support, cognitive functions, functional status and BDNF after three months from ischemic stroke onset. Therefore, a complex intervention which consists biological, psychological, social, and spiritual aspects on ischemic stroke patients needs to be developed. The "SELF-HELP Packages" was a complex intervention, abbreviated of Smart, Effort, Wellness, Feel, Happy and Power, which might be effective to terminate the negative outcomes caused by stroke (Webber \& Newby, 2015; Wills, 2011), one of which is PSD.

\section{PURPOSE}

The purpose of this study was to investigate the effect of "SELF-HELP Packages" on PSD after three months from ischemic stroke onset and its effect after confounding variables were controlled.

\section{METHODS}

\section{Research design and samples}

This study was a quasi-experiment study using pre and post-test design with a control group. The samples were 68 stroke ischemic survivors after three months from onset, who were divided evenly into the intervention and control groups, with 34 respondents in each group. The study was conducted in two government hospitals in Central Java, Indonesia for three months in 2018. The respondents in each group were separately recruited from different hospitals. The inclusion criteria were ischemic stroke survivors after three months from ischemic stroke diagnosis, no aphasia, having a good hearing, having Mini Mental Status Examination (MMSE) score of $\geq 22$. The sampling technique used purposive sampling in which researchers relied on their own judgments to choose the respondents among stroke patients. The sample selection is illustrated by Figure 1.

\section{Measurements}

Post stroke depression was assessed using GRID-HAMD 17 questionnaire as the main instrument in this study, which consists of 17 questions (Williams et al., 2008). This instrument had interview guidelines for use to establish its validity during data collection (Patrick et al., 2011). The categories for the scores were divided to two; first, patients with no PSD if the scores were $\leq 7$; and second, patients with PSD if the scores 
were $>7$. This instrument was translated to the Indonesian languages and then back translated to English using two independent translators. Face validity then was carried out to find out any discrepancies and also any changes for every statement based on the Indonesian culture. The reliability test yielded a Cronbach's alpha coefficient of 0.78 .

There were four other instruments utilized to measure confounding factors in this study. First, Multidimensional Scale of Perceived Social Support (MSPSS) was used to measure respondent's social supports. This questionnaire had three categories and used Mean+Standard Deviation to determine cut off points of the categories due to homogeneity of the data. Language validity resulted in good agreement between translated and back-translated versions while reliability test yielded a Cronbach's alpha coefficient of 0.893 .

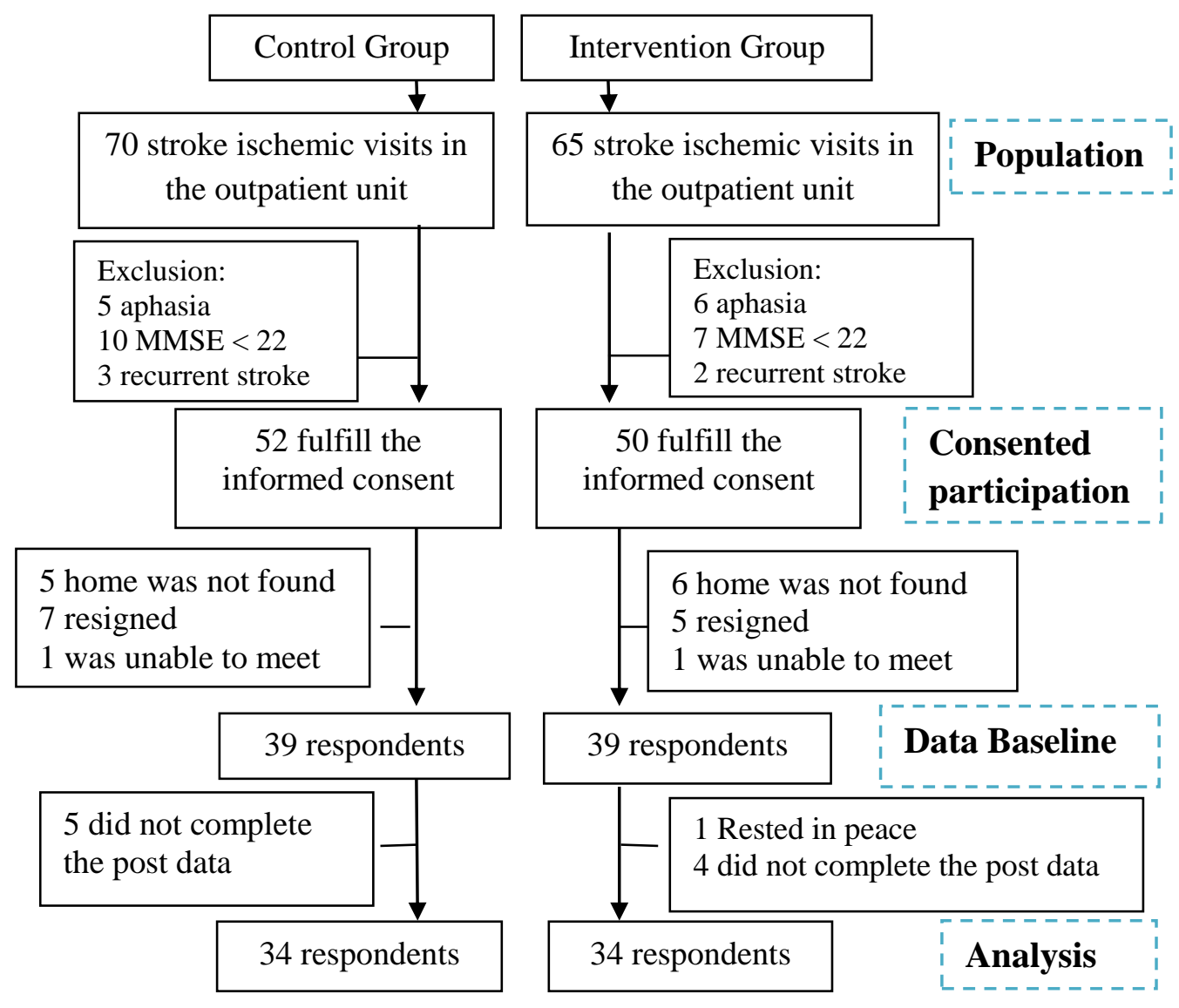

Figure 1. Participants' flowchart

Second, Mini Mental Status Examination (MMSE) was used to measure cognitive functions. MMSE consisted of six subscales of orientation, registration, attention, calculation, recall, and language. There were two categories of this questionnaire in which the scores were $\geq 28$ for no cognitive impairment and $<28$ for cognitive impairment. A reliability test showed a Cronbach's Alpha coefficient of 0.8. Third, Barthel-Index was used to measure the respondents' functional status. Barthel-Index five categories were transformed to two categories; dependent category with the 
Barthel-index scores of $<90$, and independent category with the Barthel-index scores of $\geq$ 90. The Cronbach's alpha coefficient of the Barthel-index was 0.934. Fourth, Enzyme-Linked Immunosorbent Assay (ELISA) was conducted using Emax Immunoassay System Kit (Promega; Madison, WI, USA) (Promega, 2009) to analyse BDNF from patient's blood samples. The blood samples were taken and analysed in the same day.

\section{Intervention}

The intervention of "SELF-HELP Packages" consisted of three activities which covered health education, discussion and independent activities (Aranda, 2008). "SELF-HELP Packages" were delivered in four sessions with one week apart between sessions, each of which lasted for 60-90 minutes. Prior to the data collection, eight registered nurses were recruited and trained for two days to deliver the intervention. During the intervention, booklet and self-monitoring chart were provided to the respondents while a SELF-HELP module was given to the nurses to guide them delivering the intervention. A flip chart was also used to help nurses deliver the health education. The activities in the "SELF-HELP Packages" can be seen in Table 1. Once the intervention group completed the packages, the post-tests were measured one week after the fourth session. On the other hand, the control group received standard interventions according to the hospitals and the post-tests were done on the fifth week.

Table 1. The activities of the "SELF-HELP Packages"

\begin{tabular}{|c|c|c|}
\hline Session & Activities & Media \\
\hline First session & $\begin{array}{l}\text { Focusing on the biological and psychological aspects } \\
\text { - Involving health education, demonstration and } \\
\text { discussion of biological aspect such as knowledge } \\
\text { of stroke, life styles to prevent stroke, } \\
\text { hypertension diet, ranged of motion (ROM), } \\
\text { mobilization and transfer. } \\
\text { - Facilitating for patients acceptance and } \\
\text { commitment through acceptance and } \\
\text { commitment therapy (ACT) toward } \\
\text { rehabilitations and treatments of stroke as a } \\
\text { part of psychological aspects. } \\
\text { - Independent activities of the patients during a } \\
\text { week to the next meeting. }\end{array}$ & $\begin{array}{l}\text { Booklets and self- } \\
\text { monitoring charts }\end{array}$ \\
\hline Second Session & $\begin{array}{l}\text { Focusing on the social and spiritual aspects } \\
\text { - Discussing and encouraging the social aspects, } \\
\text { such as family support, social gathering and } \\
\text { social activities of the patients during the post } \\
\text { stroke period. } \\
\text { - Discussing spiritual values of the patients and } \\
\text { religion activities, such as prayer; and developing } \\
\text { patient's spiritual competences } \\
\text { - Independent activities of the patients during a } \\
\text { week to the next meeting. }\end{array}$ & $\begin{array}{l}\text { Booklets and } \\
\text { Flipcharts } \\
\text { Booklets and self- } \\
\text { monitoring charts }\end{array}$ \\
\hline
\end{tabular}


Table 1. (Continued)

\begin{tabular}{ccc}
\hline Session & \multicolumn{1}{c}{ Activities } & \multicolumn{1}{c}{ Media } \\
\hline Third Session & $\begin{array}{l}\text { Focusing on evaluation of the patient's achievements } \\
\text { and progresses along previous weeks }\end{array}$ & \\
& $-\quad \begin{array}{l}\text { Evaluating and discussing any skill improvements } \\
\text { on each aspect. When no improvement was made, } \\
\text { another contract would be made to accomplish the } \\
\text { skills according to the patient's agreement. }\end{array}$ & $\begin{array}{l}\text { Self-monitoring } \\
\text { charts }\end{array}$ \\
& $-\quad \begin{array}{l}\text { Independent activities of the patients during a a } \\
\text { week to the next meeting. }\end{array}$ & $\begin{array}{l}\text { Booklets and self- } \\
\text { monitoring charts }\end{array}$ \\
Fourth Session & $\begin{array}{l}\text { Conducting independent activities for the patients } \\
\text { under text messaging aids for controlling }\end{array}$ & $\begin{array}{l}\text { Booklets and self- } \\
\text { monitoring charts }\end{array}$ \\
\hline
\end{tabular}

\section{Data analysis}

McNemar test, Chi-square and logistic regression were employed to analysed the data. McNemar test was used to determine the differences on dichotomous dependent variables while Chi-square test was conducted to compare PSD between groups. The logistic regression was finally utilized to measure the effect of "SELF-HELP Packages" on PSD after other confounding variables were controlled.

\section{Ethical considerations}

Ethical clearance was gained from the Health Research Ethic Committee of the Faculty of Medicine, Universitas Diponegoro (No. 596/EC/FK-RSDK/X/2017). Informed consents were obtained from all respondents before the data collection. The patients and their families were well-informed about the study before consenting their participation.

\section{RESULTS}

\section{Characteristics of respondents}

The result showed that the characteristics of respondents between intervention and control groups were homogenous (Table 2).

Table 2. Characteristics of respondents $(n=68)$

\begin{tabular}{|c|c|c|c|c|c|c|}
\hline \multirow[t]{2}{*}{ Characteristics } & \multicolumn{2}{|c|}{$\begin{array}{l}\text { Control group } \\
\quad(n=34)\end{array}$} & \multicolumn{2}{|c|}{$\begin{array}{l}\text { Intervention group } \\
\qquad(n=34)\end{array}$} & \multirow[t]{2}{*}{$X^{2}$} & \multirow[t]{2}{*}{$\rho$} \\
\hline & $f$ & $\%$ & $f$ & $\%$ & & \\
\hline \multicolumn{7}{|l|}{ Gender } \\
\hline Male & 19 & 52.8 & 17 & 47.2 & \multirow[t]{2}{*}{0.22} & \multirow[t]{2}{*}{0.808} \\
\hline Female & 15 & 46.9 & 17 & 53.1 & & \\
\hline \multicolumn{7}{|l|}{ Age } \\
\hline$\leq 60$ & 22 & 51.2 & 21 & 48.8 & \multirow[t]{2}{*}{0.04} & \multirow[t]{2}{*}{1.0} \\
\hline$>60$ & 12 & 48 & 13 & 52 & & \\
\hline \multicolumn{7}{|l|}{ Employment } \\
\hline Employed & 11 & 44.0 & 14 & 56.0 & \multirow[t]{2}{*}{0.07} & \multirow[t]{2}{*}{0.615} \\
\hline Unemployed & 23 & 53.5 & 20 & 46.5 & & \\
\hline \multicolumn{7}{|l|}{ Monthly income } \\
\hline Low & 21 & 48.8 & 22 & 51.2 & \multirow[t]{2}{*}{0.09} & \multirow[t]{2}{*}{1.0} \\
\hline High & 13 & 52.0 & 12 & 48.0 & & \\
\hline
\end{tabular}


Table 2. (Continued)

\begin{tabular}{lrrrrrr}
\hline Characteristics & \multicolumn{2}{c}{$\begin{array}{c}\text { Control group } \\
(n=34)\end{array}$} & \multicolumn{2}{c}{$\begin{array}{c}\text { Intervention group } \\
(n=34)\end{array}$} & $X^{2}$ & $\rho$ \\
\cline { 2 - 5 } & \multicolumn{1}{c}{$f$} & $\%$ & \multicolumn{1}{c}{$f$} & $\%$ & & \\
\hline Education & 31 & 49.2 & 32 & 50.8 & 0.22 & 1.0 \\
$\quad$ Low & 3 & 60 & 2 & 40 & & \\
High & & & & & & \multirow{2}{*}{0.627} \\
PSD & 17 & 50 & 14 & 41.2 & .0002 & 0.627 \\
No PSD & 17 & 50 & 20 & 58.8 & & \\
PSD & & & & &
\end{tabular}

The effect of "SELF-HELP Packages" on PSD in the intervention group

The result showed that the number of respondents who had no PSD increased from $41.2 \%$ to $68 \%$ while the number of respondents who had PSD decreased from $58.8 \%$ to $32 \%$ after "SELF-HELP Packages" intervention. It was shown that the intervention reduced the PSD in the intervention group $(p=0.004)$ (Table 3$)$.

Table 3. Differences on PSD in the intervention group $(n=34)$

\begin{tabular}{lclclc}
\hline Intervention & \multicolumn{3}{c}{ No PSD } & \multicolumn{3}{c}{ PSD } & \multirow{2}{*}{ Group } & $f$ & $\%$ & $f$ & $\%$ & \\
\cline { 2 - 5 } & 14 & 41.2 & 20 & 58.8 & $0.004^{*}$ \\
\hline Pre-test & 23 & 68 & 11 & 32 & \\
Post-test & & & & &
\end{tabular}

\section{The effect of "SELF-HELP Packages" on PSD between groups}

As seen in Table 4, there was a significant difference in the number of PSD and No PSD at post-tests between the intervention and control group $(p=0.008)$. It can be concluded that "SELF-HELP Packages" had a significant effect on decreasing PSD.

Table 4. Differences on PSD between the intervention and control group $(n=68)$

\begin{tabular}{lccccc}
\hline \multirow{2}{*}{ Groups } & \multicolumn{2}{c}{ no PSD } & \multicolumn{2}{c}{ PSD } & \multirow{2}{*}{$p$} \\
\cline { 2 - 5 } & $f$ & $\%$ & $f$ & $\%$ & $0.008^{*}$ \\
\hline Intervention $(n=34)$ & 23 & 67.6 & 11 & 32.3 & \multirow{2}{\text{Control}(n=34)}{} \\
\hline
\end{tabular}

*Chi square

The effect of "SELF-HELP Packages" on PSD after controlling the confounding factors

Logistic regression showed that "SELF-HELP Package" had no effect on PSD when other confounding variables were controlled $(p=0.075$, OR=0.288, 95\% CI 0.073-1.135). However, functional status was shown to be the most affecting factor on PSD $(p=0.034$, OR=0.34 95\% CI 0.083-0.907). 
Nurse Media Journal of Nursing, 10(3), 2020, 368

Table 5. Effects of "SELF-HELP Packages" on PSD after controlling the confounding factors $(n=68)$

\begin{tabular}{lrrrrcc}
\hline Interventions /Factors & \multicolumn{1}{c}{$B$} & \multicolumn{1}{c}{$S E$} & Wald & $p$ & OR & $95 \%$ CI \\
\hline "SELF-HELP Packages" & -1.243 & 0.699 & 3.164 & 0.075 & 0.288 & $0.073-1.135$ \\
Social Support & -1.099 & 0.629 & 3.056 & 0.080 & 0.333 & $0.097-1.142$ \\
Functional State & -1.295 & 0.611 & 4.492 & 0.034 & 0.034 & $0.083-0.907$ \\
Cognitive & -21.167 & 13579.827 & 0.999 & 0.999 & 0.000 & $0.000-$ \\
BDNF & -0.661 & 0.706 & 0.877 & 0.349 & 0.516 & $0.130-2.059$ \\
Constant & -2.310 & 0.663 & 12.126 & 0.000 & 0.099 & \\
\hline Nagelkerke R Square $=0.468 ; p=0.000$ & & & & &
\end{tabular}

\section{DISCUSSION}

This study aimed to analysed the effect of "SELF-HELP Packages" on PSD among ischemic stroke survivors after three months from onset. The result showed that "SELFHELP Packages" had a significant effect on reducing PSD after three months from onset. This result was similar with the result of a study that developed complex interventions which included support psychotherapeutic treatment, information about disease, developing daily activity schedules, coping with daily hassles, using problemsolving skills, engaging in social networks and community activities, learning relaxation techniques and community based psychosocial services (Zimmermann et al., 2014). Another study also found that a complex, nurse-led intervention, which was implemented as a collaborative care model, increased perceived self-efficacy and better clinical outcome of anxiety, depression or somatization symptoms (Zimmermann et al., 2016).

Other studies also showed similar results with this study. Mayo et al. (2015) reported that exercise and project-based activities promoting learning, leisure, and social activities among stroke showed a great gain of stroke-specific health-related quality of life. Evans-Hudnall et al. (2014) revealed that multi-intervention increased the efforts of stroke survivors to control the secondary risk factors of stroke. Stroke survivor who has been showing a good adaptation with their life, will gain a good quality of life although with a handicap (Dharma, 2015). A study by Byrne et al. (2020) also found that a complex intervention, consisting of medication adherence to statins, lifestyle behaviours and cardiovascular risk and delivered by health education session, massage and phone call, resulted in good outcomes in patients with coronary vascular diseases.

The "SELF HELP Packages" consists of biological, psychological, social and spiritual aspects. The biological aspect, which includes life style behaviour in stroke preventions, hypertension diets, range of motion (ROM), mobilization and transfer, facilitates stroke survivors to adapt in their new stroke life and reduce the risk factors of stroke (Dharma et al., 2018). Stroke knowledge (risk factors, causes, diets, treatments, and medications), daily activities, mobilization, transfer and range of motion are also claimed as parts of the biological aspects (Ebert et al., 2017).

The psychological aspect of the packages includes acceptance and commitment therapy (ACT). A study found that ACT was more likely to reduce depression (Majumdar \& Morris, 2018). Acceptance and commitment intervention leads the individual to a 
psychological flexibility. The ACT has become the protocol for chronic illness (Karekla, Karademas, \& Gloster, 2018). The flexibility leads the individuals to the adaptive process. ACT should be trained, so that the patients feel safe and comfort, and blend with present moments (stroke). ACT helps the patient in organizing the negative emotions, achieving the coping adaptive, and considering the stressor as the positive things. The actions in ACT guide the personal to step forward in thoughts. Regarding the natural emotion in responding illness, individuals cannot avoid the negative thoughts. Individuals practice in organizing the negative thoughts with stopping spontaneous reactions such as crying, feeling sad and hopeless (Khashouei, Ghorbani, \& Tabatabaei, 2016). ACT is effective in a wide range of population, such as breast cancer, (Mahdavi et al., 2017), DM type-II (Gregg, Callaghan, Hayes, \& GlennLawson, 2007; Lindholm-Olinder et al., 2015), and multiple sclerosis (Bach, Hayes, \& Gallop, 2012).

The social aspect of "SELF-HELP Packages" endorses the patients' motivation to involve in the social activities and the families' motivation to be an informational, emotional, and instrumental support. Social supports facilitate stroke survivors to adapt with post stroke activity daily living (Dharma et al., 2018). A qualitative study stated that family caregivers are playing an important role in caring for their relatives who have suffered from strokes (Agianto, 2018). A meta-analysis concluded that social supports in chronic illness reduce depression (Vallury, Jones, \& Gray, 2015).

The spiritual aspect of the packages leads the stroke survivors to have spiritual values which are gained by accepting the illness condition and by religious activities, such as prayer and praying. Spiritual wellness gained the benefits to support stroke rehabilitation (Mundle, 2015; The Joanna Briggs Institute, 2010). Another study supports that spirituality affects the quality of life (Moon \& Kim, 2013) and reduces depression among acute coronary and heart disease patients (Abdi, Soufinia, Borji, \& Tarjoman, 2019; Warber et al., 2011). Spiritual values indicate that the patients are having hope in illness (Warber et al., 2011). Furthermore, spirituality decreases the mortality risk of $18 \%$ in chronic illness (Lucchetti, Lucchetti, \& Koenig, 2011).

The "SELF-HELP Packages" in this study was delivered by health education, discussions and activities. Health education facilitated stroke survivors to meet with the new information about stroke that they need. Stroke survivors need an access to the health information, which can help them respond more quickly to health problems; comprehend their disease and treatment interventions; obtain good recovery; and reduce the chance of a new stroke (Du, Ma, \& Li, 2016). Discussion and activities help the stroke survivors adapt the new daily living (Dharma et al., 2018). Health education also contributes to the functional status of stroke (Ning \& Te, 2013), self-satisfaction, participation in treatment and rehabilitation, as well as emotional function (Lin, Yih, Shih, \& Chu, 2019; Sabariego et al., 2013).

The "SELF-HELP Package" is a nursing intervention derived from "Roy Adaptation Model" nursing theory. Post stroke depression is the negative result of adaptation in dealing with stimuli (Handayani \& Pudjonarko 2015; Hubbard \& Workman, 1998; Philip \& Harris, 2014). The result of this study would improve the nursing intervention 
protocols toward PSD among stroke survivors after three months from onset, both in the hospital and the community.

However, after the confounding factors were controlled, the result found that the "SELF-HELP Packages" had no significant effect on PSD. The confounding factors included social support, functional status, cognitive function and BDNF. It was assumed that the intervention should be conducted in a long period to achieve an impactful result. This assumption is supported by Byrne et al. (2020) and Medical Research Council (2014). Mayo \& Scott (2011) also points out that it may not be a good idea to evaluate a complex intervention though a single outcome. Stroke patients' needs have wide spread and person-varying effects which may not be best represented by the changes on a single outcome variable. Future studies require a longer period of time for the intervention and to investigate more than one outcomes.

The result of the study claimed that functional status was the most affecting factors on PSD. This result is in line with the other studies which state that functional status significantly affect the PSD (Lincoln et al., 2013; Ojagbemi \& Owolabi 2013; Stein et al., 2015; Zhang et al., 2012). A meta-analysis shows that the functional status is the risk factor of PSD after three and six months from onset (Shi, Yang, Zeng, \& Wu, 2017). Any variations in the functional status need to be controlled in gaining the clear effect of the intervention on PSD. Functional status should be homogenous at the same level.

This study has several limitations. First, there was no randomization in sample. There was only one group intervention and one group control. Thus, the effect of intervention could not be compared with other interventions. Second, there was no follow-up to evaluate the long-term effects. Nevertheless, this study showed a good estimate in the effect of "SELF-HELP Packages", a complex intervention, on PSD in ischemic stroke survivors after three months from onset.

\section{CONCLUSION}

The study concluded that "SELF-HELP Packages" significantly decreased PSD. Therefore, it is recommended for nurses to apply the "SELF-HELP Packages" in delivering nursing intervention. Future research is recommended to involve a larger size of sample with randomized controlled trial design in order to be able to generalize the results. The homogeneity should be achieved in the variable of functional status, as this is the strongest affecting factor of PSD. A longer period of time for the intervention is also recommended in order to obtain a more robust result.

\section{ACKNOWLEDGMENT}

The study was funded by the Ministry of Research, Technology and Higher Education, Indonesia.

\section{CONFLICT OF INTEREST}

No conflict of interest was declared by the authors. 


\section{REFERENCES}

Abdi, A., Soufinia, A., Borji, M., \& Tarjoman, A. (2019). The effect of religion intervention on life satisfaction and depression in elderly with heart failure. Journal of Religion and Health, 58(3), 823-832. doi:10.1007/s10943-018-0727-7

Agianto, A. (2018). Role and function of family in care of patients with stroke in the community, Indonesia. Dunia Keperawatan, 6(2). doi:10.20527/dk.v6i2.5226

Aranda, S. (2008). Designing nursing interventions. Collegian, 15(1), 19-25. doi:10.1016/j.colegn.2007.11.002

Bach, P., Hayes, S. C., \& Gallop, R. (2012). Long-term effects of brief acceptance and commitment therapy for psychosis. Behavior Modification, 36(2), 165-181. doi:10.1177/0145445511427193

Bartoli, F., Di Brita, C., Crocamo, C., Clerici, M., \& Carràl, G. (2018). Early poststroke depression and mortality: Meta-analysis and meta-regression. Frontiers in Psychiatry, 9(November), 1-7. doi:10.3389/fpsyt.2018.00530

Byrne, J. L., Dallosso, H. M., Rogers, S., Gray, L. J., Waheed, G., Patel, P., ... Khunti, K. (2020). Effectiveness of the Ready to Reduce Risk (3R) complex intervention for the primary prevention of cardiovascular disease: A pragmatic randomised controlled trial. BMC Medicine, 18(1), 1-13. doi:10.1186/s12916-020-01664-0

Chau, J. P. C., Thompson, D. R., Chang, A. M., Woo, J., Twinn, S., Cheung, S. K., \& Kwok, T. (2010). Depression among Chinese stroke survivors six months after discharge from a rehabilitation hospital. Journal of Clinical Nursing, 19(21-22), 3042-3050. doi:10.1111/j.1365-2702.2010.03317.x

De Wit, L., Putman, K., Baert, I., Lincoln, N. B., Angst, F., Beyens, H., ... Feys, H. (2008). Anxiety and depression in the first six months after stroke: A longitudinal multicentre study. Disability and Rehabilitation, 30(24), 1858-1866. doi:10.1080/09638280701708736

Dharma, K. K. (2015). Efektifitas intervensi model adaptasi paska stroke (IMAPS) terhadap respon adaptasi dan kualitas hidup pasien paska stroke [the effectiveness of post-stroke adaptation model intervention (IMAPS) on the adaptation response and the quality of life of post-stroke]. Retrieved from http://lib.ui.ac.id/detail?id=20416058\&lokasi=lokal

Dharma, K. K., Damhudi, D., Yardes, N., \& Haeriyanto, S. (2018). Increase in the functional capacity and quality of life among stroke patients by family caregiver empowerment program based on adaptation model. International Journal of Nursing Sciences, 5(4), 357-364. doi:10.1016/j.ijnss.2018.09.002

Donkor, E. S. (2018). Stroke in the 21 st century: A snapshot of the burden, epidemiology, and quality of life. Stroke Research and Treatment, 2018, 1-10. doi:10.1155/2018/3238165

Du, H. S., Ma, J. J., \& Li, M. (2016). High-quality health information provision for stroke patients. Chinese Medical Journal, 129(17), 2115-2122. doi:10.4103/03666999.189065

Ebert, D. D., Nobis, S., Lehr, D., Baumeister, H., Riper, H., Auerbach, R. P., ... Berking, M. (2017). The 6-month effectiveness of Internet-based guided self-help for depression in adults with Type 1 and 2 diabetes mellitus. Diabetic Medicine, 34(1), 99-107. doi:10.1111/dme.13173 
Evans-Hudnall, G. L., Stanley, M. A., Clark, A. N., Bush, A. L., Resnicow, K., Liu, Y., ... Sander, A. M. (2014). Improving secondary stroke self-care among underserved ethnic minority individuals: A randomized clinical trial of a pilot intervention. Journal of Behavioral Medicine, 37(2), 196-204. doi:10.1007/s10865-012-9469-2

Gbiri, C. A., Akinpelu, A. O., \& Odole, A. C. (2010). Prevalence, pattern and impact of depression on quality of life of stroke survivors. International Journal of Psychiatry in Clinical Practice, 14, 198-203. doi:10.3109/13651501003797633

Gregg, J. A., Callaghan, G. M., Hayes, S. C., \& Glenn-Lawson, J. L. (2007). Improving diabetes self-management through acceptance, mindfulness, and values: A randomized controlled trial. Journal of Consulting and Clinical Psychology, 75(2), 336-343. doi:10.1037/0022-006X.75.2.336

Guiraud, V., Gallarda, T., Calvet, D., Turc, G., Oppenheim, C., Rouillon, F., \& Mas, J.L. (2016). Depression predictors within six months of ischemic stroke: The DEPRESS Study. International Journal of Stroke, O(0), 1-7. doi:10.1177/1747493016632257

Hackett, M. L., Köhler, S., O’Brien, J. T., \& Mead, G. E. (2014). Neuropsychiatric outcomes of stroke. Lancet Neurology, 13(5), 525-534. doi:10.1016/S14744422(14)70016-X

Handayani, F., \& Pudjonarko, D. (2015). Associated factor and Predictor of Post Stroke Depression after 3 month onset: A Literature Review. The proceeding of 3rd Java International Nursing Conference. Semarang.

Handayani, F., Setyowati, Pudjonarko, D., \& Sawitri, D. R. (2019). Psychosocial associated and predictors of post stroke Depression 3-6 months after onset: A systematic review. Pakistan Journal of Medical and Health Sciences, 13(4), 12191223.

Health Office of Semarang City. (2020). Semarang City Health Profile 2019. Accessed on October 30, 2020. Retrieved from http://www.depkes.go.id/resources/download/profil/PROFIL_KAB_KOTA_2015/ 3374_Jateng_Kota_Semarang_2015.pdf

Holmgren, E., Lindström, B., Gosman-Hedström, G., Nyberg, L., \& Wester, P. (2010). What is the benefit of a high intensive exercise program? A randomized controlled trial. Advances in Physiotherapy, 12(May), 115-124. doi:10.3109/14038196.2010.491555

Hubbard, J. R., \& Workman, E. A. (1998). Handbook of Stress Medicine Editors Roanoke / Salem Residency Training Program. New York: CRC Press.

Kang, H. J., Bae, K. Y., Kim, S. W., Lee, E. H., Kim, J. T., Park, M. S., ... Kim, J. M. (2018). Impact of acute phase depression on functional outcomes in stroke patients over 1 year. Psychiatry Research, 267, 228-231. doi:10.1016/j.psychres.2018.06.026

Karekla, M., Karademas, E. C., \& Gloster, A. T. (2018). The common sense model of self-regulation and acceptance and commitment therapy: Integrating strategies to guide interventions for chronic illness. Health Psychology Review, O(0), 1-14. doi:10.1080/17437199.2018.1437550

Khashouei, M. M., Ghorbani, M., \& Tabatabaei, F. (2016). The Effectiveness of Acceptance and Commitment Therapy (ACT) on Self-Efficacy, Perceived Stress and Resiliency in Type II Diabetes Patients. Global Journal of Health Science, 9(5), 18. https://doi.org/10.5539/gjhs.v9n5p18 
Kielbergerova, L., Mayer, O.-J., Vanak, J., Bruthans, J., Wohlfahrt, P., \& Ciffkova, R. (2015). Quality of life predictors in chronic stable post-stroke patients and prognostic value of SF-36 score as a mortality surrogate. Translational Stroke Research, 6(5), 375-383. doi:10.1007/s12975-015-0418-6

Lerdal, A., Bakken, L. N., Rasmussen, E. F., Beiermann, C., Ryen, S., Pynten, S., ... Kim, H. S. (2011). Physical impairment, depressive symptoms and pre-stroke fatigue are related to fatigue in the acute phase after stroke. Disability and Rehabilitation, 33(4), 334-342. doi:10.3109/09638288.2010.490867

Li, J., Zhao, Y., Zeng, J., Chen, X., Wang, R., \& Cheng, S. (2014). Serum brain-derived neurotrophic factor levels in post-stroke depression. Journal of Affective Disorders, 168, 373-379. doi:10.1016/j.jad.2014.07.011

Lin, F. H., Yih, D. N., Shih, F. M., \& Chu, C. M. (2019). Effect of social support and health education on depression scale scores of chronic stroke patients. Medicine, 98(44), e17667. doi:10.1097/MD.0000000000017667

Lincoln, N. B., Brinkmann, N., Cunningham, S., Dejaeger, E., De Weerdt, W., Jenni, W., ... De Wit, L. (2013). Anxiety and depression after stroke: A 5 year follow-up. Disability and Rehabilitation, 35(2), 140-145. doi:10.3109/09638288.2012.691939

Lindholm-Olinder, A., Fischier, J., Fries, J., Alfonsson, S., Elvingson, V., Eriksson, J. W., \& Leksell, J. (2015). A randomised wait-list controlled clinical trial of the effects of acceptance and commitment therapy in patients with type 1 diabetes: A study protocol. BMC Nursing, 14(1), 61. doi:10.1186/s12912-015-0101-y

Loubinoux, I., Kronenberg, G., Endres, M., Schumann-Bard, P., Freret, T., Filipkowski, R. K., .. Popa-Wagner, A. (2012). Post-stroke depression: Mechanisms, translation and therapy. Journal of Cellular and Molecular Medicine, 16(9), 19611969. doi:10.1111/j.1582-4934.2012.01555.x

Lucchetti, G., Lucchetti, A. L. G., \& Koenig, H. G. (2011). Impact of spirituality/religiosity on mortality: Comparison with other health interventions. Explore: The Journal of Science and Healing, 7(4), 234-238. doi:10.1016/j.explore.2011.04.005

Mahdavi, A., Aghaei, M., Aminnasab, V., Tavakoli, Z., Besharat, M., \& Abedin, M. (2017). The effectiveness of acceptance-commitment therapy (ACT) on perceived stress, symptoms of depression, and marital satisfaction in women with breast cancer. Archives of Breast Cancer, (August), 16-23. doi:10.19187/abc.2017411623

Majumdar, S., \& Morris, R. (2018). Brief group-based acceptance and commitment therapy for stroke survivors. British Journal of Clinical Psychology, 1-21. doi:10.1111/bjc. 12198

Mayo, N. E., Anderson, S., Barclay, R., Cameron, J. I., Desrosiers, J., Eng, J. J., ... Bayley, M. (2015). Getting on with the rest of your life following stroke: A randomized trial of a complex intervention aimed at enhancing life participation post stroke. Clinical Rehabilitation, 29(12), 1198-1211. doi:10.1177/0269215514565396

Mayo, N. E., \& Scott, S. (2011). Evaluating a complex intervention with a single outcome may not be a good idea: An example from a randomised trial of stroke case management. Age and Ageing, 40(6), 718-724. doi:10.1093/ageing/afr061 
Nurse Media Journal of Nursing, 10(3), 2020, 374

Medical Research Council. (2014). Developing and evaluating complex interventions : new guidance. Accessed on October 30, 2018. Retrieved from www.mrc.ac.uk/complexinterventionsguidance

Ministry of Health The Republic of Indonesia. (2018). Laporan Nasional RISKESDAS 2018 [Report of National Fundamental Health Research 2018]. Accessed on $\begin{array}{llll}\text { October } & 3020 . & \text { Retrieved }\end{array}$ http://labdata.litbang.kemkes.go.id/images/download/laporan/RKD/2018/Laporan_ Nasional_RKD2018_FINAL.pdf

Moon, Y. S., \& Kim, D. H. (2013). Association between religiosity/spirituality and quality of life or depression among living-alone elderly in a South Korean city. Asia-Pacific Psychiatry, 5(4), 293-300. doi:10.1111/appy.12025

Mundle, R. (2015). "I should be closer to God because of this"-A case study of embodied narratives and spiritual reconstruction in spinal cord injury and stroke rehabilitation. Journal of Disability and Religion, 19(1), 30-49. doi:10.1080/23312521.2014.990551

Ning, X. S., \& Te, Z. (2013). Public and professional education on urgent therapy for acute ischemic stroke : a community-based intervention in Changsha. Neurological Sciences, 2131-2135. doi:10.1007/s10072-013-1348-2

Ojagbemi, A., \& Owolabi, M. (2013). Predictors of functional dependency after stroke in Nigeria. Journal of Stroke and Cerebrovascular Diseases, 22(8), e381-e387. doi:10.1016/j.jstrokecerebrovasdis.2013.04.015

Patrick, D. L., Burke, L. B., Gwaltney, C. J., Leidy, N. K., Martin, M. L., Molsen, E., \& Ring, L. (2011). Content validity - Establishing and reporting the evidence in newly developed patient-reported outcomes (PRO) instruments for medical product evaluation: ISPOR PRO good research practices task force report: Part 1 - Eliciting concepts for a new PRO instru. Value in Health, 14(8), 967-977. doi:10.1016/j.jval.2011.06.014

Philip, K. D., \& Harris, R. (2014). Nursing Theorist and Their Work (M. R. Alligood, Ed.). St. Louis, Missouri: Elsevier Mosby.

Promega. (2009). BDNF E max ® ImmunoAssay. USA.

Sabariego, C., Barrera, A. E., Neubert, S., Stier-jarmer, M., Bostan, C., \& Cieza, A. (2013). Evaluation of an ICF-based patient education programme for stroke patients: A randomized, single-blinded, controlled, multicentre trial of the effects on self-efficacy, life satisfaction and functioning. British Journal of Health Psychology, 18, 707-728. doi:10.1111/bjhp.12013

Sakamoto, H., Maki, N., Utsugi, A., Takata, Y., Kubota, T., Kubota, T., ... Yanagi, H. (2018). The effect of cognitive rehabilitation for post-stroke depression in longterm care health facilities: A randomized controlled trial. Clinical and Medical Investigations, 3(2), 1-7. doi:10.15761/cmi.1000157

Shi, Y., Yang, D., Zeng, Y., \& Wu, W. (2017). Risk factors for post-stroke depression: A meta-analysis. Frontiers in Aging Neuroscience, 9, 218. doi:10.3389/fnagi.2017.00218

Shi, Y.Z., Xiang, Y. T., Yang, Y., Zhang, N., Wang, S., Ungvari, G. S., ... Wang, C. X. (2015). Depression after minor stroke: Prevalence and predictors. Journal of Psychosomatic Research, 79(2), 143-147. doi:10.1016/j.jpsychores.2015.03.012

Silakarma, D., \& Sudewi, A. A. R. (2019). The role of brain-derived neurotrophic factor (BDNF) in cognitive functions. Bali Medical Journal, 8(2), 518.

doi:10.15562/bmj.v8i2.1460 
Nurse Media Journal of Nursing, 10(3), 2020, 375

Stein, J., Bettger, J. P., Sicklick, A., Hedeman, R., Magdon-Ismail, Z., \& Schwamm, L. H. (2015). Use of a standardized assessment to predict rehabilitation care after acute stroke. Archives of Physical Medicine and Rehabilitation, 96(2), 210-217. doi:10.1016/j.apmr.2014.07.403

The Joanna Briggs Institute. (2010). The Joanna Briggs Institute best practice information sheet: The psychosocial and spiritual experiences of elderly individuals recovering from a stroke. Nursing and Health Sciences, 12(4), 515518. doi:10.1111/j.1442-2018.2010.00555.x

Vallury, K. D. B., Jones, M., \& Gray, R. (2015). Do family-oriented interventions reduce poststroke depression? A systematic review and recommendations for practice. Topics in Stroke Rehabilitation, 22(6), 453-459. doi:10.1179/1074935715Z.00000000061

Warber, S. L., Ingerman, S., Moura, V. L., Wunder, J., Northrop, A., Gillespie, B. W., ..., Rubenfire, M. (2011). Healing the heart: A randomized pilot study of a spiritual retreat for depression in acute coronary syndrome patients. Explore: The Journal of Science and Healing, 7(4), 222-233. doi:10.1016/j.explore.2011.04.002

Webber, P. B., \& Newby, C. P. (2015). An introduction to reasoning and nursing theory (4th ed.). B. M. Johnson \& P. B. Webber (Eds.). Philadelphia: Wolters Kluwer Health | Lippincott Williams \& Wilkins.

Williams, J. B. W., Kobak, K. A., Bech, P., Engelhardt, N., Evans, K., Lipsitz, J., ... Pearson, J. (2008). The GRID-HAMD: Standardization of the Hamilton Depression Rating Scale. International Clinical Psychopharmacology, 23, 120129. doi:10.1097/YIC.0b013e3282f948f5

Wills, E. M. (2011). Theoretical Basis in Nursing (3rd ed.). M. McEwen \& E. M. Wills (Eds.). Philadelphia: Wolters Kluwer Health | Lippincott Williams \& Wilkins.

World Health Organization. (2019). Monitoring Health for The SDGs, sustainable development goals. World Health Organization. Retrieved from https://apps.who.int/iris/handle/10665/324835

Yuan, H. W., Wang, C. X., Zhang, N., Bai, Y., Shi, Y. Z., Zhou, Y., ... Wang, Y. J. (2012). Poststroke depression and risk of recurrent stroke at 1 year in a chinese cohort study. PLoS ONE, 7(10), e46906. doi:10.1371/journal.pone.0046906

Zhang, T., Jing, X., Zhao, X., Wang, C., Liu, Z., Zhou, Y., ... Wang, Y. (2012). A prospective cohort study of lesion location and its relation to post-stroke depression among Chinese patients. Journal of Affective Disorders, 136(1-2), e837. doi.org:10.1016/j.jad.2011.06.014

Zimmermann, T., Puschmann, E., Ebersbach, M., Daubmann, A., Steinmann, S., \& Scherer, M. (2014). Effectiveness of a primary care based complex intervention to promote self-management in patients presenting psychiatric symptoms: Study protocol of a cluster-randomized controlled trial. BMC Psychiatry, 14(1). doi:10.1186/1471-244X-14-2

Zimmermann, T., Puschmann, E., van den Bussche, H., Wiese, B., Ernst, A., Porzelt, S., ... Scherer, M. (2016). Collaborative nurse-led self-management support for primary care patients with anxiety, depressive or somatic symptoms: Clusterrandomised controlled trial (findings of the SMADS study). International Journal of Nursing Studies, 63, 101-111. doi:10.1016/j.ijnurstu.2016.08.007 